\title{
Delivering national public mental health - experience from England
}

\author{
lan F. Walker, Jude Stansfield, Lily Makurah, Helen Garnham, Claire Robson, Cam Lugton, \\ Nancy Hey and Gregor Henderson
}

(Information about the authors can be found at the end of this article.)
Received 6 June 2018

Revised 21 December 2018 Accepted 11 March 2019

( ) Ian F. Walker, Jude Stansfield, Lily Makurah, Helen Garnham,

Claire Robson, Cam Lugton, Nancy Hey and Gregor Henderson. Published by Emerald

Publishing Limited. This article is published under the Creative Commons Attribution (CC BY 4.0) licence. Anyone may reproduce, distribute, translate and create derivative works of this article (for both commercial \&

non-commercial purposes), subject to full attribution to the original publication and authors. The full terms of this licence may be seen at http://creativecommons.org/ licences/by/4.0/legalcode

This work was supported by Public Health England but no funding was received for the writing or publishing of this technical paper. The views expressed in the publication are those of the authors and not necessarily those of Public Health England or the Department of Health and Social Care, UK Government.

\begin{abstract}
Purpose - Mental health is an emerging health policy priority globally. The emphasis on closing the treatment gap in psychiatric services is now being complemented by an increasing focus on prevention and health promotion. The purpose of this paper is to describe the programmes and delivery of public mental health in England led by Public Health England (PHE), an arms-length body of the Department of Health and Social Care.

Design/methodology/approach - This technical paper outlines the general approach PHE has taken in delivering national work in public mental health and describes several key areas of work: children and young people, suicide prevention, workplace and workforce, strategic engagement with stakeholders, data and information and evidence synthesis.

Findings - A description of the various programmes and guidance documents that PHE have produced are described and referenced, which form a substantial body of work in public mental health.

Practical implications - The outputs from PHE may assist in informing the approach to public mental health that other government agencies could consider adopting. The resources described and signposted within this technical paper are publicly available for readers.

Originality/value - England is one of a small group of countries that have a track record in delivering public mental health at a national level. This paper gives a unique and detailed insight into this work.
\end{abstract}

Keywords Prevention, Public health, Policy, Wellbeing, Public mental health, Suicide prevention, Government, Mental health

Paper type Technical paper

\section{Introduction}

Mental health is an increasingly important field in global health policy (Patel and Saxena, 2014; Kleinman et al., 2016). Mental health problems make a substantial contribution to the global burden of disease, especially to years lived with disability, with depression being the largest single cause (Whiteford et al., 2013; WHO, 2017). Many governments across the globe are now measuring the wellbeing of their populations as a barometer of social progress and development (Durand, 2018).

Recent policy priorities in global mental health have focussed on closing the treatment gap: improving the proportion of individuals experiencing a mental health problem who are able to access effective psychiatric treatments locally (Eaton et al. , 2011; Patel et al., 2010). This is rightly a policy focus globally, but not alone in importance. For instance, the current global mental health action plan (WHO, 2013) also highlights, as one of its four key objectives, the implementation of strategies for the promotion and prevention of mental health. This objective falls within the field of public mental health $(\mathrm{PMH})$ which is an aspect of public health that takes an upstream approach to mental health and wellbeing and particularly focuses on mental health promotion and the prevention of mental health problems at a population level (Wahlbeck, 2015). The sign of its growing importance is demonstrated in its inclusion within the recently agreed sustainable development goals (Target 3.4: by 2030 reduce by one-third pre-mature mortality 
from non-communicable diseases through prevention and treatment, and promote mental health and wellbeing) (WHO, 2016). This is accompanied by growing evidence of the effectiveness of interventions at the population and community level to promote wellbeing and prevent mental health problems (Petersen et al., 2016; Patel et al., 2016; Jacka and Reavley, 2014). However, in its monitoring of the global mental health action plan, WHO reports that under half of member countries have two or more functioning programmes in mental health promotion or prevention (WHO, 2015).

Public Health England (PHE) is an executive agency of the Department of Health and Social care (UK Government). Since its inception in 2013, PHE has delivered national policy and programmes to promote mental health and wellbeing, prevent mental health problems, prevent suicide and address the health inequalities experienced by people living with or recovering from a mental health problem.

Given the experience within England and the development of expertise in $\mathrm{PMH}$, this paper aims to describe the approach PHE has taken to deliver policies and programmes and to outline some of the work in key areas of PMH.

\section{The national approach}

PHE provides system leadership and advice to government, provides information and expertise to the local public health system and the specialist workforce (Public Health England, 2018). The national PMH programme was developed in 2012-2013, informed by the contemporaneous national policy (HM Government, 2011), World Health Organization policy and guidance (WHO, 2002, 2012) and established theories and frameworks that explain the mental health approach in public health (Barry, 2001). The three overarching goals of PHE's programme became promotion of mental health and wellbeing across the population, prevention of mental health problems and suicide, and improving the wellbeing of people living with and recovering from mental health problems. Since PHE's inception there has been a mental-health-in-all-policies approach (WHO, 2013), informed by evidence that mental health is a determinant of overall health and wellbeing (Friedli, 2009) and calls for parity of esteem with physical health (Royal College of Psychiatrists, 2010). This involved embedding, wherever possible, mental health goals and actions into wider public health work.

In order to embed mental health into all public health, it is important to distinguish between mental health promotion and mental illness prevention (Tudor, 1996; Westerhof and Keyes, 2009). The promotion of good mental health and wellbeing in the population is an outcome in its own right and also a determinant of physical health. As such, PMH contributes to prevention of all disorders, not just mental health problems. Terminology has always been a challenge in $\mathrm{PMH}$ and developing a coherent narrative for the work was an early priority that is still relevant (Davies, 2014).

Mental health is itself determined by a wide range of inter-related factors at structural, community and individual levels (Government Office for Science, 2008). As such, mental health is prioritised as a cross-cutting programme for PHE, alongside healthy communities and health inequalities. Building connected and empowered communities and reducing inequity are both central to improving the nation's mental health. An example of the intertwining of these cross-cutting themes is the work to map the causal pathway from social inequalities to health outcomes by recognising the role of psychosocial factors and mental wellbeing (UCL Institute of Health Equity and Public Health England, 2017).

There is strong evidence of the need for public health action to be taken across the life course from preconception through early years and school-age to working age, leading to healthy productive ageing (Lynch and Smith, 2005; Marmot et al., 2010). PHE is therefore taking a life course approach to $\mathrm{PMH}$ which identifies key opportunities for minimising risk factors and enhancing protective factors through evidence-based interventions at key life stages. The complexity of mental health means that engagement with a wide range of stakeholders across sectors and government departments is a mechanism for this large-scale change. The voluntary and community sector has been a strong partner, helping the programme to be person and community-centred. The complex system approach is currently informing our work (Rutter et al., 2017). 
Whilst mental health outcomes in England are measured through the "Public Health Outcomes Framework" (suicide rates, hospital admissions for self-harm, premature mortality and employment amongst people with mental illness, subjective wellbeing, quality of life of older people, workplace sickness absence, school readiness) these are high level and affected by many mediating factors and interventions. Attributing causality to factors influencing national improvements in suicide rates or improved wellbeing to specific interventions is problematic. However, having short- and medium-term outcomes and targets is necessary and theories of change and logic models have been used. A set of indicators or outcome framework such as developed in Scotland (NHS Health Scotland, 2012) has not been agreed for England which is a limitation to the programme. Further work is needed to develop a shared understanding of a more comprehensive set of PMH outcomes with partners.

PHE's approach has resulted in many programmes of delivery, guidance documents and enabling products in $\mathrm{PMH}$ across a range of topics. The following sections describe some of this work in more detail.

\section{Examples of work PHE has undertaken}

\section{Children, young people and families}

Recent data indicate that one in eight children aged 5-18 years old in England and 1 in 6 of 17-19 year olds have a diagnosable mental health problem (NHS Digital, 2018). There is a significant body of evidence to suggest that inequalities in child development begin prenatally and in the first years of life, with cumulative and long-term impacts on adult outcomes (Marmot et al., 2010). In the UK it is estimated that around 50 per cent of the population experience at least one adverse childhood experience (ACE) (Hughes et al., 2017), with around 12 per cent experiencing four or more ACEs. Poor mental health is a prominent consequence, reaching to the next generation (NHS Health Scotland, 2017). Mental health problems in pregnancy and the first year after birth are experienced by up to 20 per cent of women (Davies, 2014). If untreated maternal mental illness during the perinatal period can adversely affect: infant cognitive, emotional and behavioural outcomes; maternal-infant bonding and quality of parenting (Hogg, 2013). Promoting mental health as an integral part of preconception care and during the perinatal period is important.

Examples of PHE's work include partnership with NHS and local government to lead the prevention work stream within the "Maternity Transformation Programme", developing a multi-disciplinary perinatal competency framework with Health Education England (The Tavistock and Portman NHS Foundation Trust, 2018). Additionally, social marketing expertise was used to develop mental health content of the "Start4Life Information Service for Parents" (www.nhs.uk/start4life).

The early years part of the life course is particularly crucial for laying the foundations for healthy development and protecting against adverse experiences through the promotion of early attachment and positive parenting (Public Health England, 2016a). Children with speech, language and communication needs are at higher risk of poorer outcomes, including their social, emotional and mental health (Bishop and Leonard, 2014). PHE has formed a partnership with Department for Education to improve early language skills and assessment, particularly for health visitors to use at 2-2.5 years assessment. In addition, PHE's focussed efforts to ensure every child is given the best start in life includes assuring local delivery of the five universal health visitor reviews (to all children under 5) as part of the "Healthy Child Programme" (Department of Health, 2009) and leadership of a cross-sector "Best Start in Life" programme.

Evidence supports a multi-level approach to building resilience at an individual level, within families and at an organisational level to help manage adversity (AYPH, 2016). PHE has taken a number of steps to promote resilience including publishing with the Association of Young People's Health a framework for a public health approach to resilience. This highlighted key evidence (Public Health England, 2016d) and the way data and intelligence is reported so as to highlight the significance of key protective factors to inform local planning (Public Health England, 2017g). PHE has also drawn on evidence about building young people's resilience to inform the development of "Rise Above" - a peer led digital platform for 11-16 year olds. This uses relevant content in creative ways, tapping into inspirational video from vloggers and YouTubers. The aim is 
to get young people talking about the things that matter to them and helping them to develop resilience skills for dealing with diverse life challenges such as cyberbullying, exam stress, body image and self-harm (Rise Above, 2018).

In England school nurses provide an important role in providing a universal non-stigmatised confidential service bridging the interface between schools, families and specialist services. School nurses provide early identification and help to navigate referral systems and pathways. Through its professional leadership role for school nursing, PHE is working to promote a focus on developing resilience and emotional wellbeing as a high impact area (Public Health England, 2014b).

There is good evidence of a reciprocal relationship between health and wellbeing and educational attainment (Bonell et al., 2014) and there is evidence that supports the effectiveness of taking a whole school/college approach in PMH to realise positive outcomes (Langford et al., 2014). PHE has taken action to raise awareness amongst senior leaders in education settings (and civil society organisations who work with them). This focussed on the evidence-based principles for whole school/system approaches to mental health and wellbeing (Children and Young People's Mental Health Coalition and Public Health England, 2015c) and their measurement (Public Health England, 2016c). PHE has also worked closely with Department of Health and Social Care and the Department for Education mental health policy teams to ensure these functions are implemented in schools through a recent UK Government green paper (Department of Health and Social Care and Department for Education, 2018).

Such a wide scope of potential work in promoting children and young people's mental health inevitably provides challenges in prioritisation. These include striking the right balance between universal and targeted approaches, local actions and national policy and between the different stages of early development. The role of PHE regional teams and their relationships with local systems is crucial in addressing some of these challenges, to complement what the national team achieves. A further challenge is the appropriate use of evidence. Studies grounded in linear models of cause and effect are problematic in setting realistic expectations concerning the measurable impact of PMH approaches in the context of complex systems (Rutter et al., 2017). This has led PHE to a re-balancing of the place of research evidence alongside service data and intelligence, the voices of children, young people and carers and insights from practice to shape initiatives.

\section{Suicide prevention}

In England, 13 people kill themselves on average every day. Suicide is the biggest killer in men under 50 years old, young people and new mothers (Department of Health and Social Care, 2017). PHE has worked within the policy framework of the cross-government "National Suicide Prevention Strategy" (HM Government, 2012) to deliver on prevention policies.

Local authorities are well placed to prevent suicide because their work on public health addresses many of the risk factors such as alcohol and drug misuse and spans efforts to address wider determinants of health such as employment and housing (Public Health England, 2016e). PHE therefore undertook system leadership to encourage local authorities to take responsibility for suicide prevention through developing multi agency partnerships, audits and plans. PHE also developed a local suicide prevention profiling tool (Public Health England, 2017b) that helps local areas to identify need and benchmark against similar areas. All local authorities now have plans in place or in final stages of development across England. PHE also supported training the local public health workforce with the development of competencies for suicide prevention and self-harm (HEE, 2018).

PHE has also provided a comprehensive synthesis of the evidence and translated this into accessible guidance on developing prevention plans (Public Health England, 2014a), high risk locations (Public Health England, 2015b) and responses to suicide clusters (Public Health England, 2015a, 2015e). Partnerships with other government agencies has led to the development of guidelines on preventing suicide in the community and custodial settings (NICE, 2018), expand the evidence base on high risk occupational groups (ONS, 2017) and higher education settings (ONS, 2018), the development of a toolkit on preventing suicides in higher education settings (Universities UK, 2018) and guidance about the role employers can have in suicide prevention and in response to a suicide in an employee (BITC, 2017a, 2017b). 
Civil society is at the heart of this work, as evidenced by the joint PHE and National Suicide Prevention Alliance work with support after suicide. This includes the co-production of a support booklet called "Help is at Hand" (Public Health England, 2016b), a practical and emotional guide for anyone affected by a suicide, as well as guidance to local public health leaders in how to provide local services that provide support for those bereaved by suicide (Public Health England, 2017f).

As with many areas of $\mathrm{PMH}$, evaluation of suicide prevention approaches can be challenging as the numbers of suicides, particularly in a local authority area are low. Identifying causality between intervention and suicide outcomes is a further challenge. More can be done but currently local areas are being supported with a self-assessment approach to evaluation of suicide prevention through a "sector-led improvement" process (LGA, 2018).

\section{Prevention concordat for better mental health}

One of the headline prevention methodologies within the recent Five Year Forward View on Mental Health (NHS England, 2016) was to establish a PHE-led "Prevention Concordat for Better Mental Health". The aim is to deliver a step change in prevention-focussed leadership and practice in every local area across England (Public Health England, 2017d). This cross-sector approach adopts evidence from outside the traditional mental health sectors and includes action on wider determinants. The cumulative effect of integrating PMH prevention and promotion into the daily business and interventions of cross-sectoral organisations provides the greatest potential for sustainable change in reducing health inequalities (Goldie et al., 2016). Recognising this, the prevention concordat scope includes local authorities and non-governmental organisations including faith groups, schools and employers. To support this initiative, PHE developed:

- a stocktake of current prevention plans and mental health joint strategic needs assessments (JSNA) to establish existing activity (Public Health England, 2017e);

- guidance that informs the development of local prevention planning arrangements (Public Health England, 2017d);

- local authority mental health champions masterclasses to grow prevention-focussed political leaders;

- a new mental health JSNA toolkit to make it easier for local areas to assess the local mental health needs of their populations (Public Health England, 2017i); and

- updated guidance on the return on investment of prevention of mental illness interventions (Public Health England, 2017c) to help local areas select and make the economic case for commissioning prevention programmes.

To date the concordat has been endorsed by 60 national organisations who have committed to take action to improve mental health (Public Health England, 2017d).

\section{Workforce development}

A key challenge for PMH initiatives is making mental health everyone's business (WHO, 2013). This requires not only engagement of a wide range of sectors but also the development of the workforce with the knowledge and skills to take action. This was an early priority for the team and following consultation with stakeholders, PHE produced a PMH leadership and workforce development framework (Stansfield, 2015; Public Health England, 2015d). It identifies 12 core principles for PMH practice and six ambitions for change covering leadership, public health expertise and the wider frontline workforce. A call to action (Public Health England, 2015f) has helped to gain support across organisations to embed the priorities for action - later developed into 20 high impact changes, 17 of which have work underway or completed. The framework was recognised within the Five Year Forward View for Mental Health (NHS England, 2016) which has led to the resourcing of a new national PMH programme within Health Education England (Health Education England, 2017; NHS England, 2017). Specific action has included delivery of a national train the trainers programme in mental wellbeing 
brief intervention resulting in 300 trainers to date across England, e-learning modules in community-centred approaches, development of $\mathrm{PMH}$ subject guides to inform specialist public health training and introductory learning for the wider workforce and development of local authority leadership through a mental health champions programme for elected representatives.

Limitations of the work include the framework being extremely broad and not focusing on a specific workforce. Further work is needed to refine the messages and principles to key audiences. To address these issues work is now underway to review impact with partners and refresh the priorities into deliverable actions.

\section{Data and information tools}

Data has underpinned everything that PHE has done. England is fortunate in the richness of data sets that inform our work in PMH. To ensure these data sets are as good as possible, we have established a National Mental Health, Dementia and Neurology Intelligence Network (NMHDNIN) hosted by PHE and working across the care system. This network of data professionals, analysts and end-users has led to the delivery of a suite of flexible data profiling tools that provide local authorities, the NHS and other planners and commissioners with the best information available on mental health. This assists local leaders to understand need and interpret and address mental health issues in a way that is relevant to them and helps drive improvements in mental health. Information can be benchmarked against other local areas, and similar populations for England. The suite available within the "fingertips platform" (Public Health England, 2017a) include interactive data sets on common mental health problems, severe mental illness, suicide prevention, co-existing substance misuse and mental health issues, children and young people's mental health and wellbeing, perinatal mental health, JSNA for mental health and wellbeing, and mental health crisis care. The mental health and wellbeing needs assessment profile has a complimentary knowledge guide that links to policy and guidance, the evidence base and further sources of data. It begins with a focus on prevention and PMH with chapters on "understanding place" and "understanding people", it then follows a life course approach with chapters on "perinatal mental health", "children and young people's mental health", "mental health of working age adults" and "mental health of older people".

We have developed a robust methodology in developing these "fingertips profiles". First, we collate relevant guidance and evidence to inform the key themes or profile domains and assess available data sets to inform tool content. This is informed by peer-reviewed research and guidance such as from the National Institute of Health and Care Excellence (NICE) and is presented to an expert reference group made up of academics, data experts, analysts and users who interpret this evidence and make expert judgements to guide the profile purpose and content. Key overall data sources are collated into data catalogues and the purpose and reason for inclusion of each metric is defined and included in the profile metadata in the final tool. Each profile is reviewed periodically with the aim of ensuring it is up-to-date and draws upon all appropriate data sets that enable it to provide a robust local overview of the relevant care pathway.

The fingertips profiles enable understanding of need and how that need is being met at a local level. Anecdotal feedback on the mental health profiles from users is generally very positive. They are well used and mental health accounts for 25 per cent of all fingertips profile use. However, they have their limitations. Their content is dictated by available data sets not by system requirements - our network is seeking to address this over time. Because the profiles bring many data sets together in one place, relating one data set to another can be confusing or sometimes misleading - for instance metrics cover different time periods (some quarterly, some annual), or based on different populations (e.g. whole population, survey sample, adults defined as $18+$ or $16-64)$ or are presented as a rate, percentage, ratio or count. Different administrative boundaries at local level also cause some difficulties. Relating data on identified need (local government geographies) to data on the effectiveness of NHS services (NHS commissioning geography) to meet that need can be particularly problematic. However, local areas have a good understanding of their local administrative boundary issues. 


\section{Workplace public mental health}

The workplace presents a good opportunity to reach people who may have either diagnosed or un-diagnosed mental health problems, including depression, to offer them support. Employee welfare is now widely acknowledged as a key driver of business success (Edmans et al., 2014) and so employers are becoming increasingly aware of the importance of looking after both the mental and physical health of their staff.

In England there has been a lot of activity in this area. Over 700 companies have signed the Time to Change employer pledge to take action to reduce the stigma of mental health at work (www.time-to-change.org.uk/get-involved/get-involved-workplace/pledged-employers). PHE and Business in the Community recently launched a mental health toolkit for employers (BITC, 2016) aimed at businesses of all sizes. This offers decision makers and line managers a roadmap for addressing mental health at work. The toolkit has been downloaded over 10,000 times.

\section{What works centre for wellbeing}

As part of the UK Coalition Government (2010-2015) policy to improve public services through evidence-based policy and practice, a network of national "What Works" centres were established in England (HM Government, 2018). With the growing importance of improving wellbeing as an ultimate policy objective (Durand, 2018), PHE was a founding partner of the What Works Centre for Wellbeing (https://whatworkswellbeing.org/) and hosted the development team as they established themselves in 2015. The What Works Centre is a cross sector, cross department partnership to understand what organisations - governments, business, communities - can do to improve wellbeing that is evidence informed and cost effective. Its focus, so far, is on collation and synthesis of the known global evidence, using the same evidence standards as used by NICE, and in the translation and dissemination of that evidence in a way that is relevant and accessible to a wide range of audiences. Where evidence gaps have been identified, the Centre works with a broad range of partners to fill the gaps. Reports have already been published looking at, amongst other topics, housing (What Works Centre for Wellbeing, 2017b), measuring impact on wellbeing (What Works Centre for Wellbeing, 2018), job quality (What Works Centre for Wellbeing, 2017c), unemployment (What Works Centre for Wellbeing, 2017e), sport and dance (What Works Centre for Wellbeing, 2017d) and conceptualising community wellbeing (What Works Centre for Wellbeing, 2017a).

\section{Conclusion}

Mental health is an important area of health policy. In many countries and previously in England the policy focus has been on scale up of effective treatment services. Globally, there is now recognition that the emphasis on treatment requires a complementary priority on population mental health and wellbeing, in terms of prevention and promotion. In England, PHE has led on the delivery of this over the last five years and has developed numerous outputs across various related topics. There is much to learn and much to do in taking an upstream approach to mental health. Collaborations with other public health institutes and foreign Governments could enhance the work further and assist in the sharing of learning to enhance global efforts to promote mental health.

\section{References}

AYPH (2016), "A public health approach to promoting young people's resilience", Association for Young People's Health, London.

Barry, M.M. (2001), "Mental health intervention spectrum", International Journal of Mental Health Promotion, Vol. 3 No. 1, pp. 25-34.

Bishop, D.V. and Leonard, L. (Eds) (2014), Speech and Language Impairments in Children: Causes, Characteristics, Intervention and Outcome, Psychology Press, London.

BITC (2016), "Mental health toolkit for employers", Business in the Community, London. 
BITC (2017a), "Crisis management in the event of a suicide: a postvention toolkit for employers", Business in the Community, London.

BITC (2017b), "Reducing the risk of suicide: a toolkit for employers", Business in the Community, London.

Bonell, C., Fletcher, A. and Anderson, R. (2014), "Why schools should promote students' health and wellbeing", British Medical Journal, Vol. 4 No. 348, p. g3078.

Davies, S. (2014), "Annual report of the chief medical officer 2013", Public Mental Health Priorities: Investing in the Evidence, Department of Health, London.

Department of Health (2009), "Healthy child programme: pregnancy and the first five years of life", Crown Copyright, London.

Department of Health and Social Care (2017), "Preventing suicide in England: third progress report of the cross-government outcomes strategy to save lives", Crown Copyright, London.

Department of Health and Social Care and Department for Education (2018), "Transforming children and young people's mental health provision: a green paper", Crown Copyright, London.

Durand, M. (2018), "Countries' experiences with well-being and happiness metrics”, The Global Happiness Council, Global Happiness Policy Report, Sustainable Development Solutions Network, New York, NY.

Eaton, J., Mccay, L., Semrau, M., Chatterjee, S., Baingana, F., Araya, R., Ntulo, C., Thornicroft, G. and Saxena, S. (2011), "Scale up of services for mental health in low-income and middle-income countries", The Lancet, Vol. 378 No. 9802, pp. 1592-603.

Edmans, A., Li, L. and Zhang, C. (2014), "Employee satisfaction, labor market flexibility, and stock returns around the world", National Bureau of Economic Research, Cambridge MA.

Friedli, L. (2009), "Mental health, resilience and inequalities", WHO, Copenhagen.

Goldie, I., Elliott, I., Regan, M., Bernal, L. and Makurah, L. (2016), "Mental health and prevention: taking local action", Mental Health Foundation, London.

Government Office for Science (2008), "Foresight report on mental capital and wellbeing", Crown Copyright, London.

Health Education England (2017), "Action Plan for Mental Health Promotion and Prevention Courses 20162020”, Crown Copyright, London.

HEE (2018), "Self-harm and suicide prevention frameworks", Health Education England, London, available at: www.hee.nhs.uk/our-work/mental-health/self-harm-suicide-prevention-frameworks

HM Government (2011), No Health without Mental Health: A Cross-Government Mental Health Outcomes Strategy for People of All Ages, Crown Copyright, London.

HM Government (2012), Preventing Suicide in England: A Cross-Government Outcomes Strategy To Save Lives, Crown Copyright, London.

HM Government (2018), "What works network", available at: www.gov.uk/guidance/what-works-network (accessed 1 November 2017).

Hogg, S. (2013), "Prevention in mind - all babies count: spotlight on perinatal mental health", NSPCC, London.

Hughes, K., Bellis, M.A., Hardcastle, K.A., Sethi, D., Butchart, A., Mikton, C., Jones, L. and Dunne, M.P. (2017), "The effect of multiple adverse childhood experiences on health: a systematic review and metaanalysis", The Lancet Public Health, Vol. 2 No. 8, pp. e356-66.

Jacka, F.N. and Reavley, N.J. (2014), "Prevention of mental disorders: evidence, challenges and opportunities”, BMC Medicine, Vol. 12 No. 75, doi: 10.1186/1741-7015-12-75.

Kleinman, A., Estrin, G.L., Usmani, S., Chisholm, D., Marquez, P.V., Evans, T.G. and Saxena, S. (2016), "Time for mental health to come out of the shadows", The Lancet, Vol. 387 No. 10035, pp. 2274-5.

Langford, R., Bonell, C.P., Jones, H.E., Pouliou, T., Murphy, S.M., Waters, E., Komro, K.A., Gibbs, L.F., Magnus, D. and Campbell, R. (2014), "The WHO health promoting school framework for improving the health and well-being of students and their academic achievement”, Cochrane Database of Systematic Reviews, No. 4, doi: 10.1002/14651858.CD008958.pub2.

LGA (2018), "Sector-led improvement in public health: progress and potential", Local Government Association, London, available at: www.adph.org.uk/category/phsystem/sli/ 
Lynch, J. and Smith, G.D. (2005), "A life course approach to chronic disease epidemiology”, Annual Review of Public Health, Vol. 26, pp. 1-35.

Marmot, M., Allen, J., Goldblatt, P., Boyce, T., Mcneish, D. and Grady, M. (2010), "Fair society, healthy lives (the marmot review)", Institute of Health Equity, London.

NHS Digital (2018), "The Mental Health of Children and Young People in England, 2017", Crown Copyright, London.

NHS England (2016), "The five year forward view for mental health: a report from the independent mental health taskforce to the NHS in England", Crown Copyright, London.

NHS England (2017), "Stepping forward to 2020/21: The Mental Health Workforce Plan for England”, Crown Copyright, London.

NHS Health Scotland (2012), "Outcomes framework for Scotland's Mental Health Improvement Strategy", NHS Health Scotland, Edinburgh, available at: www.healthscotland.com/uploads/documents/ 18979outcomes_Framework_for_MH\%20July_2012.pdf

NHS Health Scotland (2017), "Tackling the attainment gap by preventing and responding to ACES", NHS Health Scotland, Edinburgh.

NICE (2018), "Preventing suicide in community and custodial settings", NICE Guideline [NG105], National Institute for Health and Care Excellence, London.

ONS (2017), "Suicide by occupation, England: 2011 to 2015", Office for National Statistics, London, available at: www.ons.gov.uk/peoplepopulationandcommunity/birthsdeathsandmarriages/deaths/articles/ suicidebyoccupation/england2011to2015

ONS (2018), "Estimating suicide among higher education students, England and Wales: Experimental Statistics", Office for National Statistics, London, available at: www.ons.gov.uk/peoplepopulationandcommunity/ birthsdeathsandmarriages/deaths/articles/estimatingsuicideamonghighereducationstudentsenglandandwalesex perimentalstatistics/2018-06-25

Patel, V. and Saxena, S. (2014), "Transforming lives, enhancing communities - innovations in global mental health", New England Journal of Medicine, Vol. 370 No. 6, pp. 498-501.

Patel, V., Chisholm, D., Parikh, R., Charlson, F.J., Degenhardt, L., Dua, T., Ferrari, A.J., Hyman, S., Laxminarayan, R. and Levin, C. (2016), "Addressing the burden of mental, neurological, and substance use disorders: key messages from disease control priorities”, The Lancet, Vol. 387 No. 10028, pp. 1672-85.

Patel, V., Maj, M., Flisher, A.J., Silva, M.J., Koschorke, M., Prince, M., Tempier, R., Riba, M., Sanchez, M. and Campodonico, F.D. (2010), "Reducing the treatment gap for mental disorders: a WPA survey", World Psychiatry, Vol. 9 No. 3, pp. 169-76.

Petersen, I., Evans-Lacko, S., Semrau, M., Barry, M.M., Chisholm, D., Gronholm, P., Egbe, C.O. and Thornicroft, G. (2016), "Promotion, prevention and protection: interventions at the population-and community-levels for mental, neurological and substance use disorders in low-and middle-income countries", International Journal of Mental Health Systems, Vol. 10 No. 30, available at: https://doi.org/10.1186/s13033-016-0060-z

Public Health England (2014a), "Suicide prevention: developing a local action plan”, Crown Copyright, London.

Public Health England (2014b), "School aged years 5 to 19 high impact area 1: resilience and emotional wellbeing", Crown Copyright, London.

Public Health England (2015a), "Preventing suicide: lesbian, gay, bisexual and trans young people”, Crown Copyright, London.

Public Health England (2015b), "Preventing suicides in public places: a practice resource", Crown Copyright, London.

Public Health England (2015c), "Promoting children and young people's emotional health and wellbeing: a whole school approach”, Crown Copyright, London.

Public Health England (2015d), "Public mental health leadership and workforce development framework", Crown Copyright, London.

Public Health England (2015e), "Suicide prevention: identifying and responding to suicide clusters", Crown Copyright, London. 
Public Health England (2015f), "Public mental health leadership and workforce development framework: call to action”, Crown Copyright, London, available at: https://assets.publishing.service.gov.uk/government/uploads/ system/uploads/attachment_data/file/736582/Call_to_Action_3.pdf

Public Health England (2016a), "Health matters: giving every child the best start in life", HM Government (UK), London, available at: www.gov.uk/government/publications/health-matters-giving-every-child-the-beststart-in-life/health-matters-giving-every-child-the-best-start-in-life (accessed 1 November 2017).

Public Health England (2016b), "Help is at hand: support after someone may have died by suicide", Crown Copyright, London.

Public Health England (2016c), "Measuring and monitoring children and young people's mental wellbeing: a toolkit for schools and colleges", Crown Copyright, London.

Public Health England (2016d), "The mental health of children and young people in England", Crown Copyright, London.

Public Health England (2016e), "Local suicide prevention planning: a practice resource”, Crown Copyright, London.

Public Health England (2017a), "Fingertips: public health profiles", Crown Copyright, London, available at: https://fingertips.phe.org.uk/

Public Health England (2017b), "Fingertips: suicide prevention profile”, Crown Copyright, London, available at: https://fingertips.phe.org.uk/profile-group/mental-health/profile/suicide (accessed 1 November 2017).

Public Health England (2017c), "Mental health services: cost-effective commissioning", Crown Copyright, London.

Public Health England (2017d), "Prevention concordat for better mental health: consensus statement”, Crown Copyright, London, available at: www.gov.uk/government/publications/prevention-concordat-for-bettermental-health-consensus-statement/prevention-concordat-for-better-mental-health

Public Health England (2017e), "Stocktake of local mental health prevention planning arrangements", Crown Copyright, London.

Public Health England (2017f), "Support after a suicide: a guide to providing local services", Crown Copyright, London.

Public Health England (2017g), "Health behaviour in school age children (HBSC): data analysis", Crown Copyright, London, available at: www.gov.uk/government/publications/health-behaviour-in-school-agechildren-hbsc-data-analysis

Public Health England (2017i), "Better mental health: JSNA toolkit", Crown Copyright, London, available at: www.gov.uk/government/collections/prevention-concordat-for-better-mental-health

Public Health England (2018), "About us", Crown Copyright, London, available at: www.gov.uk/government/ organisations/public-health-england/about

Rise Above (2018), "Rise above”, available at: https://riseabove.org.uk/ (accessed 1 November 2017).

Royal College of Psychiatrists (2010), "No health without public mental health: a case for action”, RCPsych, London.

Rutter, H., Savona, N., Glonti, K., Bibby, J., Cummins, S., Finegood, D.T., Greaves, F., Harper, L., Hawe, P., Moore, L. and Petticrew, M. (2017), "The need for a complex systems model of evidence for public health", The Lancet, Vol. 390 No. 10112, pp. 2602-4.

Stansfield, J. (2015), "Confidence, competence and commitment: public health England's leadership and workforce development framework for public mental health", Journal of Public Mental Health, Vol. 14 No. 4 , pp. 180-4.

The Tavistock and Portman NHS Foundation Trust (2018), "A competency framework for perinatal mental health", Tavistock and Portman NHS Trust, London, available at: https://tavistockandportman.nhs.uk/ training/medical-education/competency-framework-perinatal-mental-health/

Tudor, K. (1996), Mental Health Promotion: Paradigms and Practice, Routledge, London.

UCL Institute of Health Equity and Public Health England (2017), "Psychosocial pathways and health outcomes: informing action on health inequalities", Crown Copyright, London.

Universities UK (2018), "Suicide-safer universities", Universities UK, London, available at: www.universitiesuk. ac.uk/policy-and-analysis/reports/Pages/guidance-for-universities-on-preventing-student-suicides.aspx 
Wahlbeck, K. (2015), "Public mental health: the time is ripe for translation of evidence into practice", World Psychiatry, Vol. 14 No. 1, pp. 36-42.

Westerhof, G. and Keyes, C. (2009), "Mental illness and mental health: the two continua model across the lifespan", Journal of Adult Development, Vol. 17 No. 2, pp. 110-9.

What Works Centre for Wellbeing (2017a), "Building community wellbeing: a theory of change", What Works Centre for Wellbeing, London.

What Works Centre For Wellbeing (2017b), "Housing and Wellbeing: Rapid Scoping Review", What Works Centre for Wellbeing, London.

What Works Centre For Wellbeing (2017c), "Job quality and wellbeing: what needs to happen alongside job re-design so organisations can improve wellbeing and performance?”, What Works Centre for Wellbeing, London.

What Works Centre For Wellbeing (2017d), "Sport and dance: evidence review", What Works Centre for Wellbeing, London.

What Works Centre For Wellbeing (2017e), "Unemployment, (re)employment and wellbeing: how does unemployment affect our wellbeing?", What Works Centre for Wellbeing, London.

What Works Centre For Wellbeing (2018), "How to Measure Your Wellbeing Impact", What Works Centre for Wellbeing, London.

Whiteford, H.A., Degenhardt, L., Rehm, J., Baxter, A.J., Ferrari, A.J., Erskine, H.E., Charlson, F.J., Norman, R.E., Flaxman, A.D., Johns, N., Burstein, R., Murray, C.J.L. and Vos, T. (2013), "Global burden of disease attributable to mental and substance use disorders: findings from the global burden of disease study 2010", The Lancet, Vol. 382 No. 9904, pp. 1575-86.

WHO (2002), Prevention and Promotion in Mental Health, World Health Organization, Geneva.

WHO (2012), Mental Health Action Plan 2013-2020, World Health Organization, Geneva.

WHO (2013), Health in All Policies: Framework for Action, World Health Organization, Geneva.

WHO (2015), Mental Health ATLAS 2014, World Health Organization, Geneva.

WHO (2016), World Health Statistics 2016: Monitoring Health for the SDGs Sustainable Development Goals, World Health Organization, Geneva.

WHO (2017), Depression and Other Common Mental Disorders: Global Health Estimates, World Health Organization, Geneva.

\section{Further reading}

Centre for Mental Health (2017), Meeting The Need: What Makes A 'Good' JSNA for Mental Health, Centre for Mental Health, London.

Davies, S. (2015), "Annual report of the chief medical officer, 2014", The Health of the 51\%: Women, Department of Health, London.

Goodman, A., Joyce, R. and Smith, J.P. (2011), "The long shadow cast by childhood physical and mental problems on adult life", Proceedings of the National Academy of Science, Vol. 108 No. 15, pp. 6032-7.

Gupta, S., Methuen, C., Kent, P., Chatain, G., Christie, D., Torales, J. and Ventriglio, A. (2016), "Economic development does not improve public mental health spending", International Review of Psychiatry, Vol. 28 No. 4, pp. 415-9.

Ham, C., Baird, B., Gregory, S., Jabbal, J. and Alderwick, H. (2015), "The NHS under the coalition government", Part one: NHS reform, The King's Fund, London.

Knapp, U., Ardino, V., Brimblecombe, N., Evans-Lacko, S., lemmi, V., King, D., Snell, T., Murguia, S., Mbeah-Bankas, H., Crane, S., Harris, A., Fowler, D., Hodgekins, J. and Wilson, J. (2016), Youth Mental Health: New Economic Evidence, London School of Economics and Political Science, London.

ONS (2016), Overview of the UK Population, Office for National Statistics, London.

Prince, M., Patel, V., Saxena, S., Maj, M., Maselko, J., Phillips, M.R. and Rahman, A. (2007), "No health without mental health", The Lancet, Vol. 370 No. 9590, pp. 859-77. 
Public Health England (2017h), "Prevention concordat for better mental health: prevention planning resource for local areas", Crown Copyright, London.

Richards, M. and Abbott, R. (2009), "Childhood Mental Health and Life Chances In Post-War Britain: Insights From Three National Birth Cohort Studies”, Smith Institute, London.

Saxena, S., Thornicroft, G., Knapp, M. and Whiteford, H. (2007), "Resources for mental health: scarcity, inequity, and inefficiency", The Lancet, Vol. 370 No. 9590, pp. 878-89.

\section{Author Affiliations}

Ian F. Walker is based at Global Public Health Team, Public Health England, London, UK.

Jude Stansfield is based at National Public Mental Health Team, Public Health England, London, UK.

Lily Makurah is based at National Public Mental Health Team, Public Health England, London, UK.

Helen Garnham is based at National Public Mental Health Team, Public Health England, London, UK.

Claire Robson is based at National Children Young People and Families Team, Public Health England, London, UK.

Cam Lugton is based at National Mental Health Dementia and Neurology Intelligence Network, Public Health England, London, UK.

Nancy Hey is based at What Works Centre for Wellbeing, London, UK.

Gregor Henderson is based at Health Improvement Directorate, Public Health England, London, UK.

\section{Corresponding author}

lan F. Walker can be contacted at: ian.walker@phe.gov.uk

For instructions on how to order reprints of this article, please visit our website: 